Int. J. Morphol.,

33(3):826-830, 2015.

\title{
Anatomical Reproducibility through 3D Printing in Cranio-Maxillo-Facial Defects
}

\author{
Reproducibilidad Anatómica a través de Impresión 3D en Defectos Cranio-Maxilo-Faciales
}

\author{
Paulo Hemerson de Moraes*; Sergio Olate ${ }^{* * * * * *}$; Mario Cantín ${ }^{* * * *}$; Adriano Freitas Assis ${ }^{* * * * *}$; \\ Edson Santos $^{* * * * * * *}$; Filipe de Oliveira Silva ${ }^{* * * * * * *}$ \& Lucas de Oliveira Silva ${ }^{* * * * * * * * *}$
}

\begin{abstract}
DE MORAES, P. H.; OLATE, S.; CANTIN, M.; ASSIS, A. F.; SANTOS, E.; SILVA, F. O.; SILVA, L. O. Anatomical reproducibility through 3D printing in cranio-maxillo-facial defects. Int. J. Morphol., 33(3):826-830, 2015.

SUMMARY: The planning and 3D reconstruction in craniofacial defects based on anatomical principles of symmetry and passive adaptation has evolved radically the past few years. This article recounts the possibility to develop personalized and extensive craniofacial implants. We present a case of a patient with a 10-year trauma sequel evolution; the patient lost the right frontal bone, supraorbital wall and part of the temporal fossa. From the computerized tomography, and by using Materialise software (3-Matic and Mimics). Subsequently, the printing was performed using the virtual planning with a laser printer in titanium where the piece was elaborated with the determined specifications in the planning; surgery was performed without complications in which the implant was placed via a coronal approach, which did not require any type of adaptation. After a two-year follow-up we observed a correct position, symmetry, absence of infection or any other alteration. It is concluded that the planning and 3D printing are suitable to perform craniofacial reconstructions with a low morbidity, shorter surgical time, and with an adequate facial symmetry and aesthetic return.
\end{abstract}

KEY WORDS: 3D printing; Selective laser melting; Facial implant.

\section{INTRODUCTION}

Bone lesions that cause deformities on the normal craniofacial anatomy are complex to be resolved due to the aesthetic and functional considerations involved. The anatomical complexity of the area requires high levels of adaptation of any utilized system. The conventional method being utilized for the reconstruction of these defects are based on bone graft that is capable of covering and completing the defects, or with the useof osteosysnthesis materials previously manipulated and adapted as titanium meshes or plates (Jalbert et al., 2014).

Partial resections of the skull, naso-orbital and mandibular reconstructions are complex to resolve due to its anatomical characteristics and its posterior function that can result in enophthalmia, persistent diplopia or alterations on the facial symmetry (Gaillard et al., 1997; Leake et al., 2005; Chambless et al., 2012; Kelly et al., 2005; Sandalcioglu et al., 2005).

Jointly with an adequate manufacture of the craniomaxillo-facial implants, a standard procedure based on the 3D study of the tomography and virtual surgery permits the adequate resection and semi manufactured planning of the shape and type of implants with an adequate precision range.

Titanium is a biocompatible material with a long time use. Its characteristics indicate it as a low cost material with no manufacture complications, sterilization and manipulation. Different anatomic parts in shape and size can be reconstructed with this technology (Scolozzi et al., 2007)

Division of Oral and Maxillofacial Surgery, Casa de Saúde de Santos, São Paulo, Brazil

** Division of Oral and Maxillofacial Surgery, Universidad de La Frontera, Temuco, Chile.

**** Center for Biomedical Research, Universidad Autónoma de Chile, Temuco, Chile.

**** $\quad$ Facultad de Odontología, Universidad de La Frontera, Temuco, Chile.

***** Division of Oral and Maxillofacial Surgery, Escola Bahiana de Medicina e Saúde Pública, Salvador, Brazil.

******* Instituto SENAI de Inovação em Sistemas de Manufatura, FIESC - SENAI/SC, Santa Catarina, Brazil.

******** Associates of Science, Lone Star College, Houston, United States.

*********Bology Program, University of Houston - Downtown, Houston, United States.

Research partially funded by Universidad de La Frontera DI14-0049 
making its systematic use in the craniofacial reconstruction more frequent.

With the advance of technology it is possible to print 3D metal shapes of the geometry desired through the Selective Laser Melting Technology in the health area. Selective Laser Melting Technology (SLM) uses a powerful 3D printing technology, to shape the desired metal geometry by melting metal powder layer by layer. The metal used in the creation of the customized implant is Titanium $\mathrm{Ti}-6 \%$ $\mathrm{Al}-4 \%$, wt $\%$ (Ti64 degree 23) with a low oxygen content. An ideal combination is achieved by having a biocompatible metal, titanium, designed at any desired geometric shape for a perfect customized fit. With the advances in heath technology, the work of the Selective Laser Melting Technology has allowed treatment of clinical cases that were previously practically impossible to treat due to their complexity. With the use of the SLM technology, the use of various materials, a high range of complexity on the customizations, reduced manufacture time is possible. This article will present a high complexity case of a facial trauma patient who waited 10 years due to insufficient technology available. With the SLM technology it was possible to create a perfect fit titanium implant returning and improving the patient's facial functionality and aesthetic.

\section{CASE REPORT}

A 35-year-old male patient presented a facial trauma injury of 10 years; the patient presented an evident alteration on the frontal bone area (supraorbital wall, lateral orbital wall and anterior frontal sinus wall. A replacement system with titanium implant (URI by Bioconnect, Brazil) was designed for this patient.

Planning protocol. The TC images were used to obtain the $3 \mathrm{D}$ reconstruction through a virtual planning software (3-Matic and Mimics, Belgium). Thereafter, the customized implant modeling was on top of the $3 \mathrm{D}$ reconstruction. Therefore, it

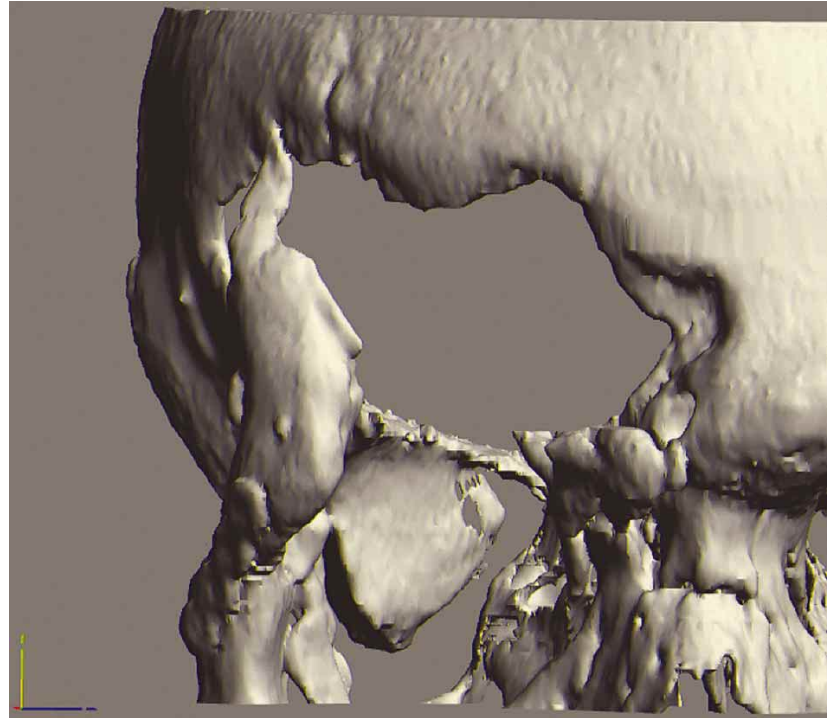

Fig 1. Frontal view showing frontal bone and orbital defect. The patient presented a facial trauma with cranial fracture.

was possible to accurately reproduce the patient's anatomical particularities during the modeling (Fig. 1).

Impression protocol. The cranial/orbital implant was modeling in the software (Figs. 2A, 2B and 2C); a variety of models were studied, with different to screw insertion and implant position; the aim at this stage is to find symmetry with the left side and good position with functional and esthetic components (Figs. 3 and 4). After the modeling, archives are generated that will be sent to the 3D laser printer to be printed through the Selective Laser Melting Technology (Fig. 4).

Surgical protocol. The implant printed in titanium (Fig. 5) was an identical replica of the software plan. This case was with a coronal approach to expose the bone defect with the oral and maxillofacial team and the neurosurgical team to realize the brain approach. After the surgical approach, the customization was easily installed without the necessity of any adaptation. The lengths of the screw

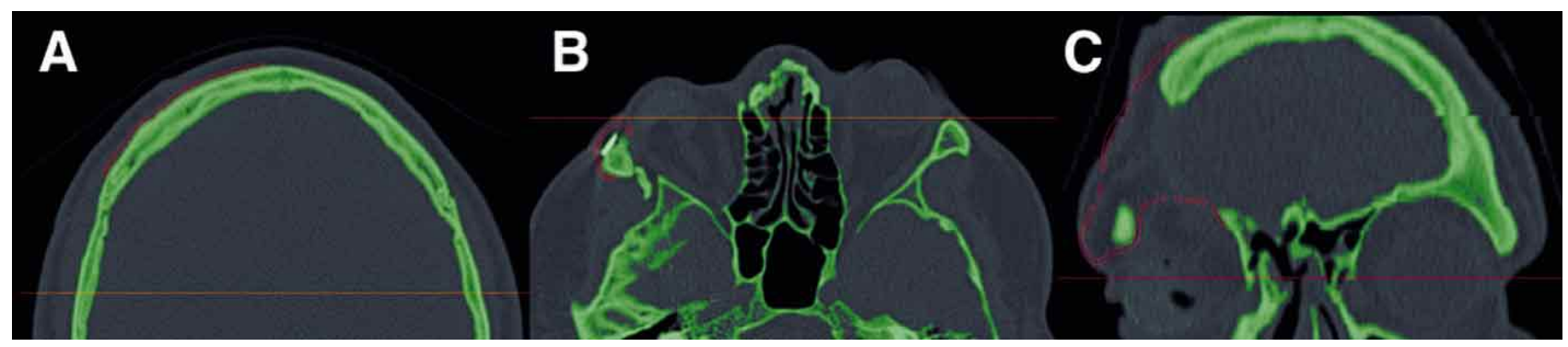

Fig 2.A) Axial view showing a precise outline of the customized implant, B) Axial view showing the symmetry of the implant and the options in position. C) Coronal view showing symmetrical rehabilitation of the skull and face through customization. 
were standardized previously in the planning process and the selected areas to make the screw insertion. The customization simplified the surgical procedure, reduced surgical time, and offered pre-visualization of the post surgical results compared to what was virtually planed, obtaining an excellent anatomy. After 2 years, the implant is in position, without complications, infections or deficiencies in the position (Fig. 6).

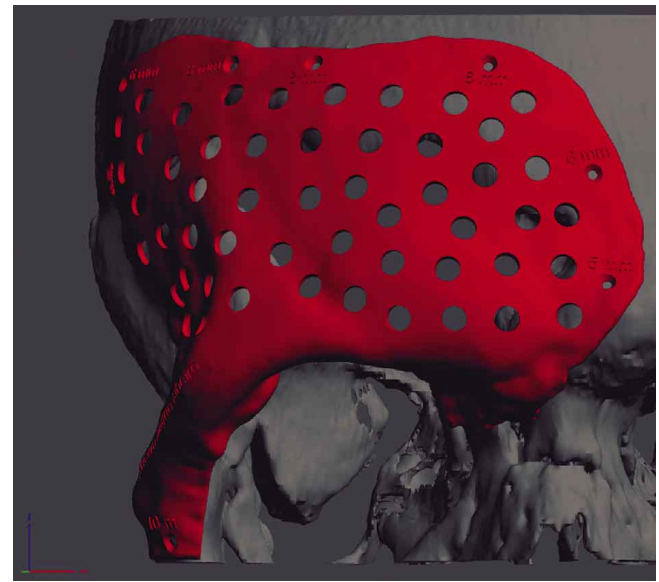

Fig 3. Frontal view showing frontal customization with satisfactory rehabilitation, realized with virtual planning.

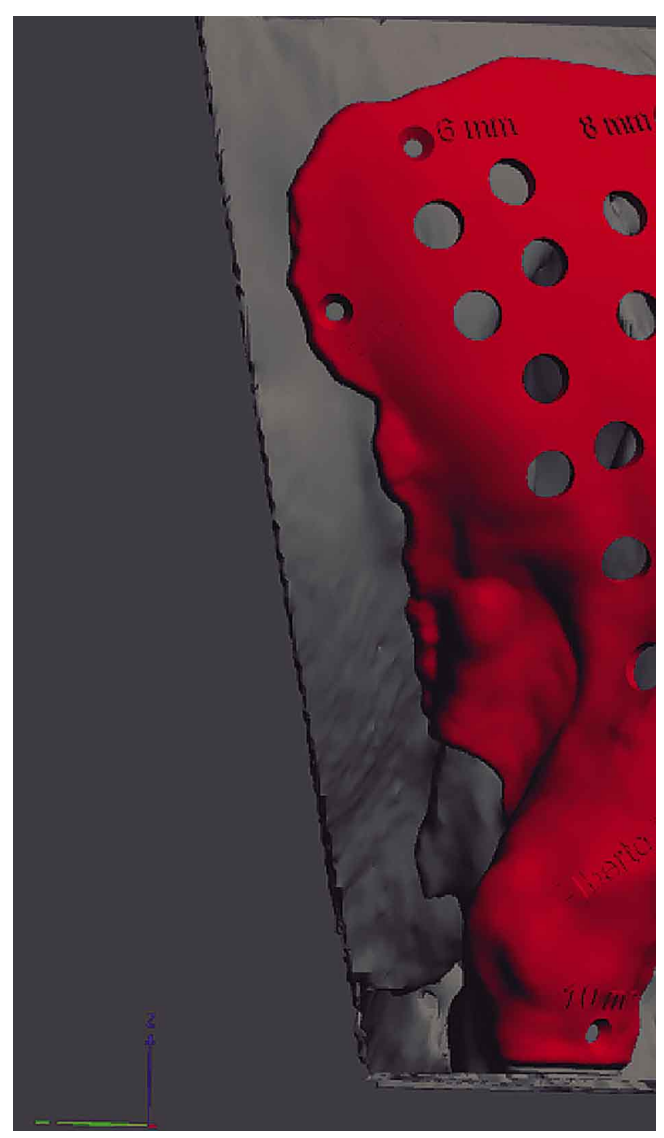

Fig 4. Lateral view showing frontal customization with satisfactory rehabilitation, realized with virtual planning.

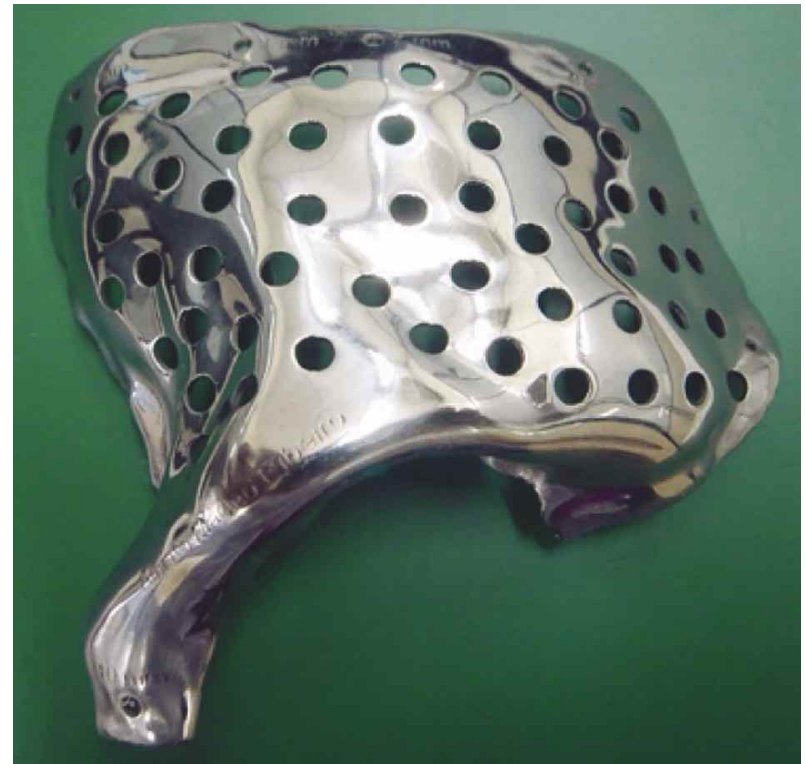

Fig 5. Frontal customized implant made with Selective Laser Melting Technology as identical replica of the software planning.

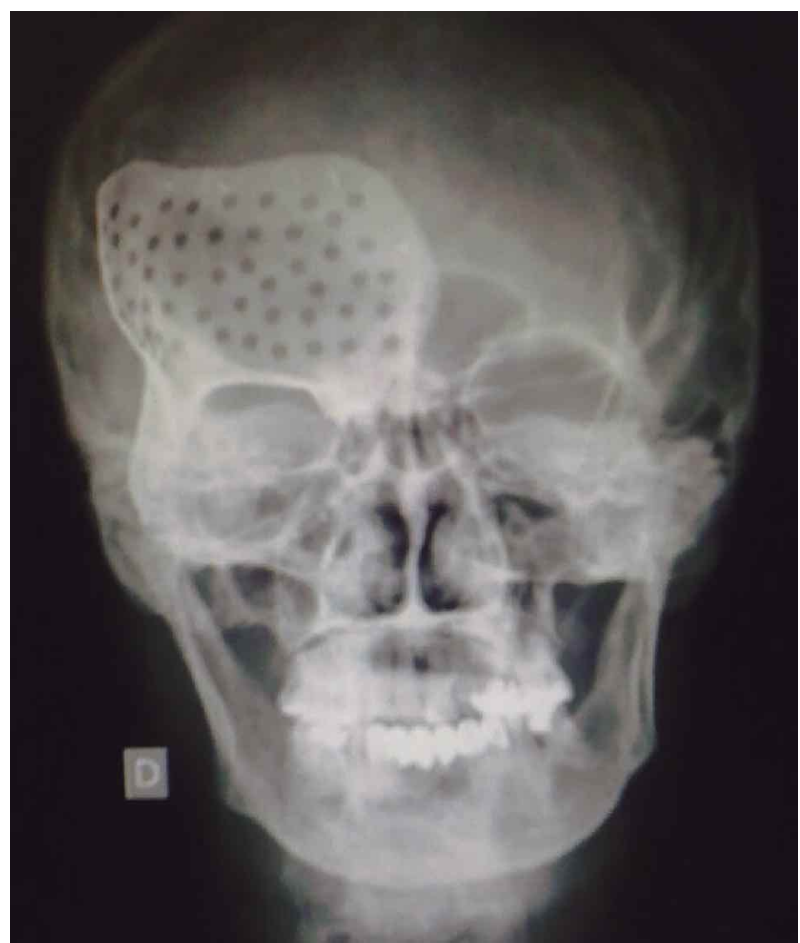

Fig 6. Radiographic (postero-anterior) showing the position and stabilization of the implant 2 year later. Symmetry in width and orbital size is obtained. 


\section{DISCUSSION}

Although the computer aided designed (CAD) has been utilized in the industry, its use in surgery has been limited (Hassfeld \& Mühling, 2001). The industrial process on CAD begins with the design of the idea to then work over the model created on CAD. The virtual model is manufactured in a direct or indirect form (Ibrahim et al., 2009; Cantín et al., 2015). In surgery, medicine and odontology, the process on CAD begins with the computerized tomography of the patient (Rudman et al., 2011). The images used in this process require a compatibility with some shapes until the precision of the models are acceptable to the stereolithographic model (Ibrahim et al.), although in the transfer and processing of information, for example in STL archives, there could exist a loss of data (Huotilainen et al., 2013).

The stereolithographic model utilizes tridimensional CAD (3D-CAD); limited studies have shown the effect of the combined use of the prototype and 3D-CAD, in which Lopez-Henredia et al. (2008) utilized a titanium scaffold with prototype techniques and Klein \& Glatzer (2006) built a glass and bioceramic implant for orbital reconstruction. Jalbert $e t$ al. showed a series of cases utilizing resection and reconstruction on a single step, viewed on a virtual surgery preview and printed implants of polyetheretherketone, showed a loss of structural anatomic fidelity on both the cranio and naso-orbital-ethmoidal reconstructions.

Stoor et al. (2014) designed implants for orbital floor reconstruction using 3D CAD technology in 12 patients, obtaining an integrate orbital structure through the installation on the "mirroring" beside the patient; with this overlaying of the images he was able to virtually reconstruct the necessary implants to recuperate the zone's morphology, designing implants between 0.5 and $0.8 \mathrm{~mm}$ of thickness; the implants were installed using direct vision and the fixation was achieved with 2.0 system screws. The intervened surgical time was of $1.17 \mathrm{~h}$ and in the maxilla-orbital resection cases was $5.65 \mathrm{~h}$, significantly reducing the surgical time by $3 \mathrm{~h}$ in comparison to the times when implants were stocks and required an intraoperative adaptation step.

The system's evolution on prototypes for its preparation and surgical planning, for example on orthognathic surgery, has been efficient and effective (Kim et al., 2011); however, great part of systems are utilized to replicate normal clinical process in a virtual environment. The new system proposal and the cases presented in this report are oriented to develop surgical planning and to reproduce anatomical replicas with precision that show a substantial advance on the model replacement development.

Recently, an article published by Mazzoni et al. (2015), established in orthognathic surgery the development of osteotomy guides and osteotomy plates printed to find the desired surgical movement; in these cases it was not used the model surgery (virtual or manual) due to the entire process being developed based on movement simulation of the computerized tomography (simulation in the teeth and bone and not in dental cast), with the adaptation of the plates completed within the same virtual model. The results revealed precision not only on the osteotomy guide but on the plates installed during the surgery as well.

These results, as well as the case presented, demonstrate qualitative and quantitative advances in surgeries of patients with craniofacial defects; the initial incorporation of this technology could be economically costly in comparison to the conventional models and styles (Saijo et al., 2009), but in the short run, process translate to a reduction in laboratory work hours, time of operation, and surgical morbidity (Gateno et al., 2011).

The precision delivered by implants based on the 3D printing respect the normal anatomy and it is based on the defective anatomy, showing that our results are promising for the precision in facial reconstruction.

DE MORAES, P. H.; OLATE, S.; CANTIN, M.; ASSIS, A. F.; SANTOS, E.; SILVA, F. O.; SILVA, L. O. Reproducibilidad anatómica a través de impresión 3D en defectos cranio-maxilo-faciales. Int. J. Morphol., 33(3):826-830, 2015.

RESUMEN: La planificación y reconstrucción 3D en defectos craneofaciales se basa en principios anatómicos de simetría y pasividad en la adaptación, evolucionando rápidamente en los últimos años. El presente articulo presenta la posibilidad de rehabilitación de un paciente con trauma importante gracias a un implante craneofacial extenso. Se presenta el caso de un sujeto con evolución de 10 años de una secuela de trauma, donde perdió el hueso frontal, pared supraorbitaria y parte de la fosa temporal. A partir de una tomografía computadorizada, utilizando un software de planificación Materialise (3-Matic and Mimics) se construyó un modelo virtual a través de un implante de pieza única para cubrir íntegramente el defecto; se planificó la posición junto a la cantidad y longitud de tornillos a utilizar. A continuación se realizó la impresión de la pieza mediante una impresora laser de titanio donde la pieza fue construida según las especificaciones de la planificación; la cirugía fue realizada sin complicaciones en el cual el implante fue instalado a través de un acceso coronal sin necesidad de ningún tipo de adaptación. Después de dos años de seguimiento se observa una posición correcta, simétrica y en ausencia de infecciones u otro tipo de alteración. Se concluye que la planificación e impresión 3D es viable de realizar en reconstrucción craneofacial con baja morbilidad, disminución del tiempo quirúrgico, obteniendo una adecuada simetría y estética facial. 


\section{REFERENCES}

Cantín, M.; Muñoz, M. \& Olate, S. Generation of 3D tooth models based on three-dimensional scanning to study the morphology of permanent teeth. Int. J. Morphol., 33(2):782787, 2015.

Chambless, L. B.; Mawn, L. A.; Forbes, J. A. \& Thompson, R. C. Porous polyethylene implant reconstruction of the orbit after resection of spheno-orbital meningiomas: a novel technique. J. Craniomaxillofac. Surg., 40(1):e28-32, 2012.

Gaillard, S.; Pellerin, P.; Dhellemmes, P.; Pertuzon, B.; Lejeune, J. P. \& Christiaens, J. L. Strategy of craniofacial reconstruction after resection of spheno-orbital "en plaque" meningiomas. Plast. Reconstr. Surg., 100(5):1113-20, 1997.

Gateno, J.; Xia, J. J. \& Teichgraeber, J. F. New 3-dimensional cephalometric analysis for orthognathic surgery. J. Oral Maxillofac. Surg., 69(3):606-22, 2001.

Hassfeld, S. \& Mühling, J. Computer assisted oral and maxillofacial surgery--a review and an assessment of technology. Int. J. Oral Maxillofac. Surg., 30(1):2-13, 2001.

Huotilainen, E.; Jaanimets, R.; Valásek, J.; Marcián, P.; Salmi, M.; Tuomi, J.; Mäkitie, A. \& Wolff, J. Inaccuracies in additive manufactured medical skull models caused by the DICOM to STL conversion process. J. Craniomaxillofac. Surg., 42(5):e259-65, 2013.

Ibrahim, D.; Broilo, T. L.; Heitz, C.; de Oliveira, M. G.; de Oliveira, H. W.; Nobre, S. M.; Dos Santos Filho, J. H. \& Silva, D. N. Dimensional error of selective laser sintering, three-dimensional printing and PolyJet models in the reproduction of mandibular anatomy. J. Craniomaxillofac. Surg., 37(3):167-73, 2009.

Jalbert, F.; Boetto, S.; Nadon, F.; Lauwers, F.; Schimidt, E. \& Lopez, R. One-step primary reconstruction for complex craniofacial resection with PEEK custom-made implants. J. Craniomaxillofac. Surg., 42(2):141-8, 2014.

Kelly, C. P.; Cohen, A. J.; Yavuzer, R. \& Jackson, I. T. Cranial bone grafting for orbital reconstruction: is it still the best? J. Craniofac. Surg., 16(1):181-5, 2005.

Kim, B. C.; Lee, C. E.; Park, W.; Kim, M. K.; Zhengguo, P.; Yu, H. S.; Yi, C. K. \& Lee, S. H. Clinical experiences of digital model surgery and the rapid-prototyped wafer for maxillary orthognathic surgery. Oral Surg. Oral Med. Oral Pathol. Oral Radiol. Endod., 111(3):278-85, 2011.

Klein, M. \& Glatzer, C. Individual CAD/CAM fabricated glassbioceramic implants in reconstructive surgery of the bony orbital floor. Plast. Reconstr. Surg., 117(2):565-70, 2006.
Leake, D.; Gunnlaugsson, C.; Urban, J. \& Marentette, L. Reconstruction after resection of sphenoid wing meningiomas. Arch. Facial Plast. Surg., 7(2):99-103, 2005.

Lopez-Heredia, M. A.; Sohier, J.; Gaillard, C.; Quillard, S.; Dorget, M. \& Layrolle, P. Rapid prototyped porous titanium coated with calcium phosphate as a scaffold for bone tissue engineering. Biomaterials, 29(17):2608-15, 2008.

Mazzoni, S.; Bianchi, A.; Schiariti, G.; Badiali, G. \& Marchetti, C. Computer-aided design and computer-aided manufacturing cutting guides and customized titanium plates are useful in upper maxilla waferless repositioning. J. Oral Maxillofac. Surg., 73(4):701-7, 2015.

Rudman, K.; Hoekzema, C. \& Rhee, J. Computer-assisted innovations in craniofacial surgery. Facial Plast. Surg., 27(4):358-65, 2011.

Saijo, H.; Igawa, K.; Kanno, Y.; Mori, Y.; Kondo, K.; Shimizu, K.; Suzuki, S.; Chikazu, D.; Iino, M.; Anzai, M.; Sasaki, N.; Chung, U. I. \& Takato, T. Maxillofacial reconstruction using custommade artificial bones fabricated by inkjet printing technology. J. Artif. Organs, 12(3):200-5, 2009.

Sandalcioglu, I. E.; Gasser, T.; Mohr, C.; Stolke, D. \& Wiedemayer, H. Spheno-orbital meningiomas: interdisciplinary surgical approach, resectability and long-term results. $J$. Craniomaxillofac. Surg., 33(4):260-6, 2005.

Scolozzi, P.; Martinez, A. \& Jaques, B. Complex orbito-frontotemporal reconstruction using computer-designed PEEK implant. J. Craniofac. Surg., 18(1):224-8, 2007.

Stoor, P.; Suomalainen, A.; Lindqvist, C.; Mesimäki, K.; Danielsson, D.; Westermark, A. \& Kontio, R. K. Rapid prototyped patient specific implants for reconstruction of orbital wall defects. J. Craniomaxillofac. Surg., 42(8):1644-9, 2014.

Correspondence to:

Paulo Hemerson de Moares

Division of Oral and Maxillofacial Surgery

Casa de Saúde de Santos

São Paulo

BRAZIL

\section{Email: contato@drpaulodemoraes.com sergio.olate@ufrontera.cl}

Received: 11-06-2015

Accepted: 19-07-2015 